M./Lorieux $\cdot$ M.-N./Ndjiondjop $\cdot A$ A $\%$ Ghesquière

\title{
A first interspecific Oryza sativa $\times$ Oryza glaberrima microsatellite-based genetic linkage map
}

Received: 1 June 1991/ Accepted: 22 June 1999

\begin{abstract}
Oryza glaberrima is an endemic African cultivated rice species. To provide a tool for evaluation and utilisation of the potential of $O$. glaberrima in rice breeding, we developed an interspecific $O$. glaberrimaxOryza sativa genetic linkage map. It was based on PCR markers, essentially microsatellites and STSs. Segregation of markers was examined in a backcross $(O$. sativa/O. glaberrimallo. sativa) population. Several traits were measured on the $\mathrm{BC}_{1}$ plants, and major genes and QTLs were mapped for these traits. Several of these genes correspond well to previously identified loci. The overall map length was comparable to those observed in indicaxjaponica crosses, indicating that recombination between the two species occurs without limitation. However, three chromosomes show discrepancies with the indicaxjaponica maps. The colinearity with intraspecific maps was very good, confirming previous cytological observations. A strong segregation-distortion hot spot was observed on chromosome 6 near the waxy gene, indicating the presence of $s_{10}$, a sporo-gametophytic sterility gene previously identified by Sano (1990). The main interests of such a PCR-based map for African rice breeding are discussed, including gene and QTL localisation, marker-assisted selection, and the development of interspecific introgression lines.
\end{abstract}

Key words $O$. glaberrima $O$ O sativa $\cdot$ Rice . Genetic maps - Microsatellites - Sequence-tagged sites · Interspecific hybridisation - Gene/QTL mapping . Segregation distortion

\section{Communicated by H.F. Linskens}

M. Lorieux ( M. M.N. Ndjiondjop · A. Ghesquière IRD (ex-Orstom), GeneTrop Laboratory, BP 5045,

34032 Montpellier cedex, France

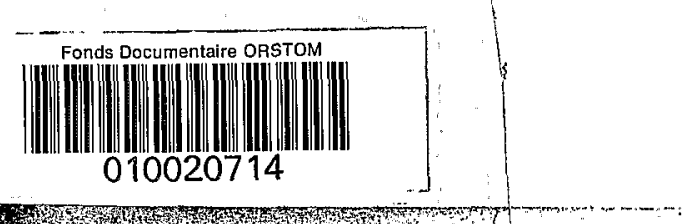

\section{Introduction}

Oryza glaberrima Steud. is the African cultivated rice species. It is of economical importance only in West Africa. Its domestication from Oryza breviligulata A. Chev. \& Roehr was independent to that of Oryza sativa (Portères 1950; Second 1982). O. glaberrima is separated from $O$. sativa by a strong reproductive barrier, including pollen sterility as well as female sterility (Pham and Bougerol 1993; Sano 1985, 1990; Sano et al. 1979).

Although $O$. glaberrima accessions present unfavourable traits, such as high shattering or lodging susceptibility, it is of great interest to study segregation and introgression events between $O$. sativa $\times O$. glaberrima. First, $O$. glaberrima accessions often show superior values for several agronomic traits under poor management conditions as well as for resistance to biotic (viruses, nematodes, insects) or abiotic (acidity, iron toxicity, drought) stresses (Attere and Fatokun 1983; Sano et al. 1984; Ghesquière et al. 1997; Reversat and Destombes 1998). Second, for quantitative traits where $O$. glaberri$m a$ is equal or inferior to $O$. sativa, we can expect transgressions in interspecific progeny, meaning that favourable alleles may come from O. glaberrima. Hence, the identification of favourable alleles from $O$. glaberrima at the genes or QTLs (quantitative trait loci) responsible for these traits would be of great value for breeding new $O$. sativa cultivars. Finally, another benefit of such studies would be the assessment of the genetic basis of the sterility system observed between the two species.

Several saturated genetic linkage maps based on molecular markers have been developed for rice, using indica $\times$ japonica or $O$. sativa $\times O$. longistaminata crosses (Causse et al. 1994; McCouch et al. 1988; Harushima et al. 1998). However, no extended linkage study has so far been reported between the two cultivated rice species; only linkage studies on small portions of the genome have been carried using morphological markers (Sano 1990). A molecular linkage map based on $O$. sativa $\times O$. glaberrima progeny would represent a very useful tool for several studies: (1) localising genes or QTLs of interest from $O$. 
$x$ 
glaberrima, providing the basis for marker-assisted selection (MAS), (2) localising sterility loci between molecular markers in order to easily screen large progenies for fertility, (3) systematically surveying the genetic recombination between the two species over all the genome, and (4) monitoring the development of introgressed genetic material with the help of molecular markers.

To be useful for all these aspects, a genetic map has to follow several criteria: technical criteria such as rapidity, simplicity, robustness, transferability and cost of the marker technology and methodological criteria such as efficient and rapid checking of advanced-generation plants for some specific chromosomal regions. To fit these requests, we initiated the development of a genetic map based on microsatellite and sequence-tagged site (STS) markers, which have recently been published for rice (Ghareyazie et al. 1993; Wu and Tanksley 1993; Inoue et al. 1994; Akagi et al. 1996; Panaud et al. 1996; Chen et al. 1997). These markers present several advantages: they are simple to generate, they are codominant and they are specific for loci on known linkage groups. Moreover, microsatellites are extremely polymorphic, permitting one, for example, to compare different rice maps in order to maximise the percentage of common markers between maps.

Here we report on the development of an interspecific (O. sativa $\times O$. glaberrima) microsatellite-based rice genetic map and its comparison to previously published intraspecific microsatellite maps.

\section{Materials and methods}

Population development and trait evaluation

We developed a backcross population from the cross IR64/TOG5681//IR64. IR64 (O. sativa, indica subspecies) is the most widespread irrigated variety in the world and was obtained from IRRI (the Philippines). TOG5681 is a photosensitive $O$. glaberrima cultivar found to be highly resistant to Rice yellow mottle virus (RYMV) Attere and Fatokun 1983; Ndjiondjop et al. 1999) and to several nematode species (Meloidogyne spp., Heterodera sacchari) (Reversat and Destombes 1998). A total of 144 $\mathrm{BC}_{1}$ individuals were obtained. This population will hereafter be referred to as the $\mathrm{BC}_{1}$ population. Although the main aim of this study was to develop an interspecific map, several traits were measured in the population in order to search for genes or QTLs for these traits. The entire population was measured for height, tillering, flowering time in decreasing day length, awning, and the coloration of stem base and stigma (see Table 2 for details on measurements). A subset of the population was also measured for the number of primary and secondary branches on the panicles.

\section{Molecular analyses}

The DNAs of parents, the $F_{1}$ hybrid, and $77 \mathrm{BC}_{1}$ individuals were isolated from lyophilised leaves using the CTAB method (Murray and Thompson 1980).

To generate simple sequence length polymorphism (SSLP), we used the microsatellite primer sequences published by Akagi et al. (1996); Chen et al. (1997); Panaud et al. (1996) and Wu and Tanksley (1993). PCR conditions were similar to those of Chen et al. (1997) except that $0.4 \mu \mathrm{Ci}$ of $[\alpha-33 \mathrm{P}]$ dATP was incorporated during the PCR reaction. PCR products were run on $6 \%$ polyacrylamide gels and the gels exposed to X-ray films (Kodak Biomax) for $7 \mathrm{~h}$.
Primer aliquots or sequences for STS markers were kindly provided by J. Bennett from IRRI (Ghareyazie et al. 1993). These sequences correspond to the RG (genomic) and $\mathrm{RZ}$ (CDNA) probes already mapped on the interspecific $O$. sativa $\times O$. longistaminata saturated map (Causse et al. 1994). Other STS primer sequences were used as published in Inoue et al. (1994). This set of 63 STSs correspond to restriction fragment length polymorphism (RFLP) markers mapped on the indicaxjaponica saturated map (Kurata et al. 1994; Harushima et al. 1998). PCR and migration conditions were as described in Ghesquière et al. (1997). Polymorphism was revealed either by migration of amplification products or after enzyme restriction.

A few amplified fragment length polymorphism (AFLP) and random amplified polymorphic DNA (RAPD) markers were also added to the map. For AFLP, the standard protocol was followed (Vos et al. 1995). For RAPD, we used the protocol described in Ghesquière et al. (1997).

\section{Map construction}

The map was estimated by multipoint analysis (Lander and Green 1987), using MapMaker v. 3.0 (Lander et al. 1987). Conversion of recombination fractions into centimorgans (cM) was obtained using Kosambi's mapping function (Kosambi 1944). This map function is the one most commonly used for rice genetic mapping, and using it systematically permits a direct comparison between different rice maps.

A comparison with the two main RFLP-based indicaxjaponica microsatellite maps (Akagi et al. 1996; Chen et al. 1997, hereafter referred to as $\mathrm{RIL}_{1}$ and $\mathrm{DH}_{1}$ populations, respectively) was established on the basis of common microsatellite loci. STS markers could aIso be used to establish the comparison, as they correspond either to RFLP markers mapped on the microsatellite maps, or to markers on the saturated RFLP genetic maps (Xiao et al. 1992; Causse et al. 1994; Harushima et al. 1998) which have numerous markers in common with the microsatellite maps.

Marker segregations were checked for deviations from an expected 1:1 ratio. As segregation distortion may affect the correct estimation of recombination fractions (Lorieux et al. 1995), we estimated recombination fractions between markers showing deviations from Mendelian expectations using appropriate models. Computations were done using MapDisto, a program developed for such situations (http://www.mpl.ird.fr/ lorieux).

According to their segregation mode, the genes and QTLs responsible for the measured traits were mapped either by conventional Mendelian mapping using MapMaker 3.0 or by interval mapping using MapMaker/QTL 1.1(Lander and Botstein 1989). Significant interval mapping tests were confirmed by Kruskall and Wallis tests using MapQTL 2.4 (van Ooijen 1992). The correspondence with previously located genes (Kinoshita.1995) was also examined.

\section{Results}

\section{Marker efficiency}

As expected, microsatellite markers showed a high polymorphism. Among 159 non-redundant primer couples, $94(60 \%)$ gave SSLPS and 65 couples (40\%) either gave faint or bad amplifications or else monomorphic patterns. On the other hand, STS markers gave a low polymorphism, even after restriction by 4-base cutters. Indeed, among 171 available primer couples, 150 (88\%) gave faint or bad amplifications or else monomorphic patterns. The remaining $21(12 \%)$ couples gave polymorphic patterns. 
Table 1 Microsatellite markers showing total cosegregation in the present work and their correspondance with previous studies

\begin{tabular}{lccl}
\hline Pairs $^{\mathrm{a}}$ & Chromosome & Distance $^{\mathrm{b}}$ & Reference $^{\mathrm{e}}$ \\
\hline OSR19-OSR25 & 6 & 0 & $\mathrm{~A}$ \\
OSR28-OSR29 & 9 & 0 & $\mathrm{~A}$ \\
OSR9A-G357 & 2 & 0 & $\mathrm{~A}$ \\
RM211-RM233A-RM236 & 2 & $<3$ & $\mathrm{P}$ \\
RM20a-RM4a & 12 & $<3$ & \\
OSR26a-RM48 & 2 & & \\
RM12-RM17 & 12 & 0 & $\mathrm{~W}$ \\
RM163-RM164 & 5 & 2.8 & $\mathrm{C}$ \\
RM232-RM251 & 3 & 22 & $\mathrm{C}$ \\
RM168-RM49 & 3 & 4.4 & \\
RM42a-RM223 & 8 & & \\
\hline
\end{tabular}

a Cosegregating microsatellites in our map

b Interval size in original mapping work (in cM)

c Original mapping work which showed cosegregation or linkage between microsatellites. A: Akagi et al. 1996; C: Chen et al. 1997; P: Panaud et al. 1996; W: Wu and Tanksley 1993

\section{Genome coverage}

The map comprised 129 markers (94 SSLPs, 21 STSs, 11 AFLPs and 3 RAPDs), representing 112 discrete marker loci. The total map length was of $1923 \mathrm{cM}$. The mean interval length is thus about $17 \mathrm{cM}$.

The genome coverage was about the same as that of the two main microsatellite maps. However, it is somewhat limited, especially for chromosomes 4 and 10, due to the number of available markers (Fukui and lijima 1991; Chen et al. 1997). Also, the end of the short arm of chromosome 7 could not be covered due to the lack of polymorphism with available markers.

Some STS markers were helpful to fill gaps between microsatellite loci (i.e. G144 on chromosome 3, RG143 on chr. 4, G342 on chr. 6, G278 on chr. 8, G103 on chr. 9).

\section{Redundancy and new loci}

Several microsatellites showed a total cosegregation in the $\mathrm{BC}_{1}$ population. In several cases, these cosegregations were either also found, or else corresponded to tightly linked markers, in previous studies. In other cases, cosegregation was found between markers originally mapped in differents studies (Table 1).

The markers OSR17 and RM12, whose map positions were unknown, were mapped in the present study on chromosomes 2 and 12, respectively. Moreover, several microsatellite primer couples generated new loci: RM260 was monomorphic for the locus on chromosome 11 in the $\mathrm{DH}_{1}$ map, but generated a marker on chromosome 12 that we called RM260b in the $\mathrm{BC}_{1}$ map. Likewise, RM42 and RM81 generated new loci on chromosome 5 (RM42b and RM81c), and RM3 generated two loci on chromosomes 3 and 9 (RM3c and RM 3 b, respectively).

\section{Genome colinearity and recombination}

$A$ very good colinearity was observed between the $B C_{1}$ map and the intraspecific $\mathrm{DH}_{1}$ and $\mathrm{RIL}_{1}$ maps (Fig. 1). A small number of very localised inversions of marker orders were observed, which were not statistically significant. For instance, on chromosome 2, the microsatellites RM208 and RM 213 were inverted between the (IR64/Azucena) map and this work, but these markers were not placed with good confidence on the (IR64/ Azucena) map (LOD <2).

To compare the linkage-group sizes, we have considered the maximum common interval size (MCIS) between two markers shared by both maps. This represents a better parameter than the total linkage group size (TLGS) for a comparison of map sizes, because it eliminates errors due to the lack of genome coverage at chromosome ends. The respective lengths (TLGS and MCIS) of the 12 chromosomes in the $\mathrm{BC}_{1}$ and $\mathrm{DH}_{1}$ maps are reported in Table 3. It appears that the majority of linkage groups had globally similar sizes. Moreover, the two genomes had similar total sizes (1923 and $1935 \mathrm{cM}$ ). This could be related to the fact that the genetic distance between $O$. glaberrima and $O$. sativa is about the same as the distance between the 'ancestral' indica and japonica subspecies of $O$. sativa (Second 1985). However, considering the MCIS, chromosomes 6 and 11 showed a notably lower mean recombination rate, and chromosome 5 showed a larger mean recombination rate in the interspecific hybrid. Moreover, recombination differences between the $\mathrm{BC}_{1}$ and $\mathrm{DH}_{1}$ maps could vary along the same chromosome (e.g. chromosome 3). Similar observations have already been made, for instance, in the O. sativa $\dot{X} O$. longistaminata $\mathrm{BC}_{1}$ population (Causse et al. 1994).

\section{Segregation distortion}

Segregation distortion is frequently observed in rice mapping studies (Causse et al. 1994; Kurata et al. 1994; Lorieux et al. 1996; Xu et al. 1997; McCouch et al. 1988). In our study, strong segregation distortion was observed on chromosome 6 close to the microsatellite markers OSR19 and OSR25, both contained in the waxy gene (Fig. 1). This is due to the presence of a sporo- 


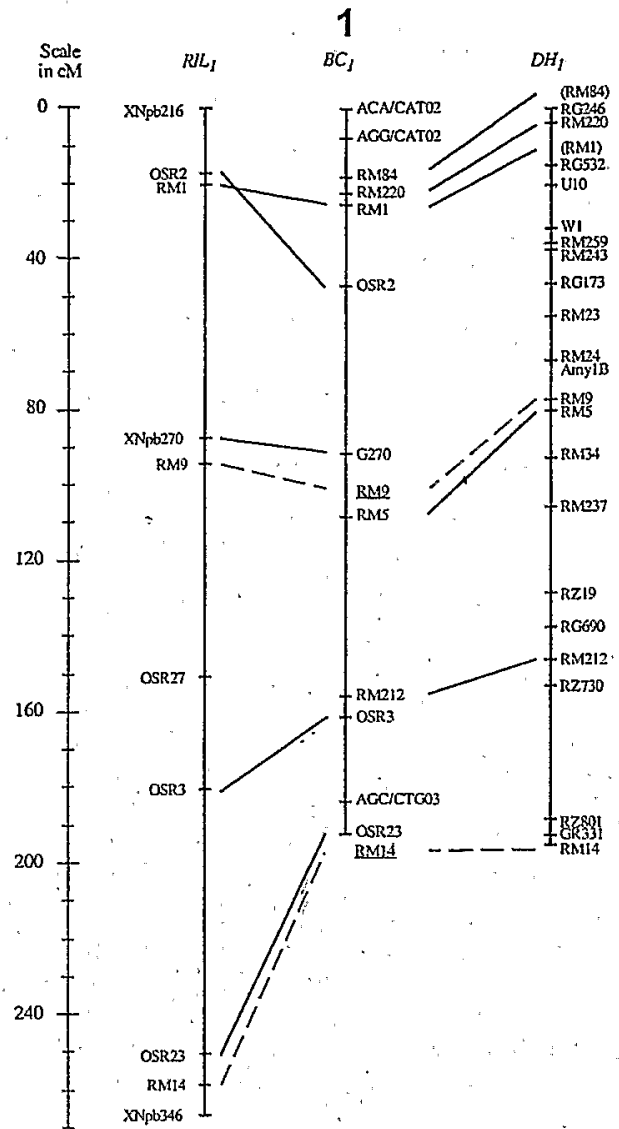

4

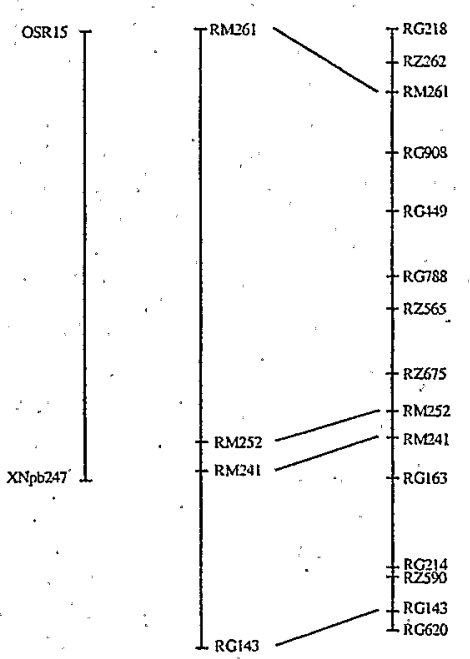

2

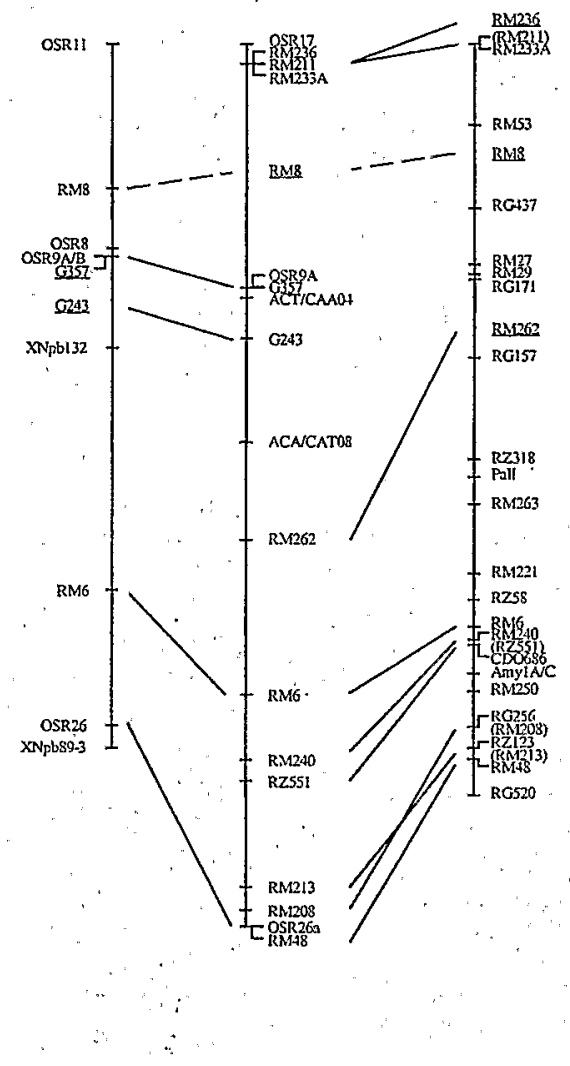

3

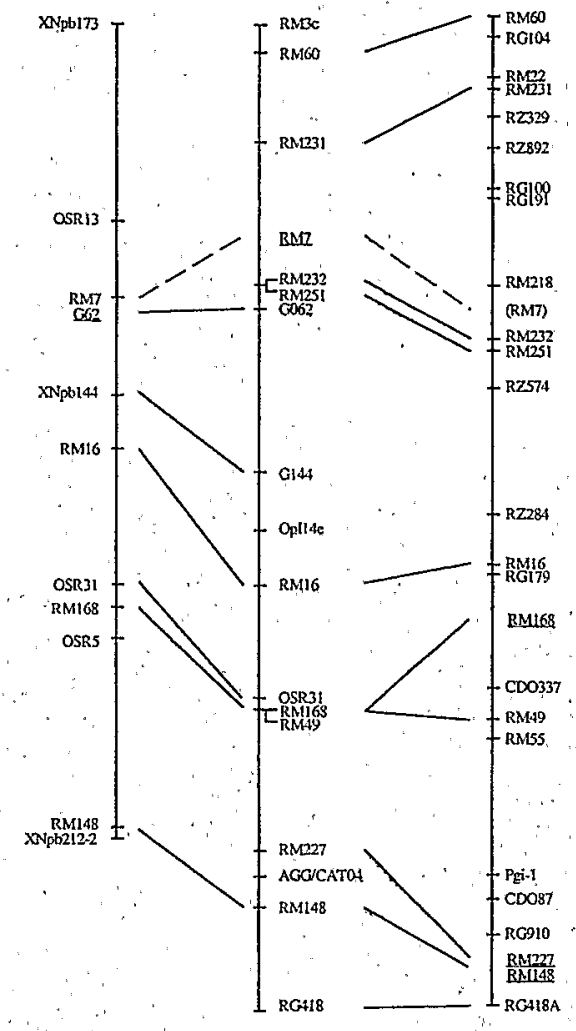

5

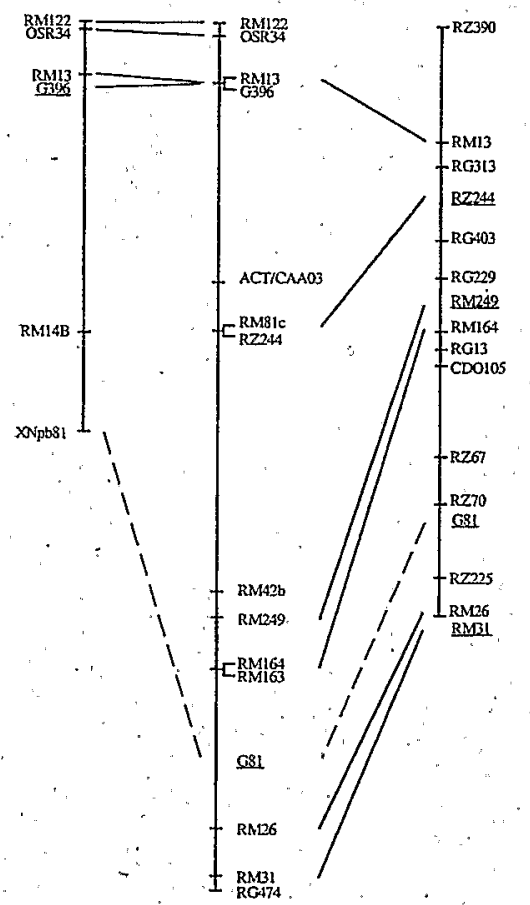

6

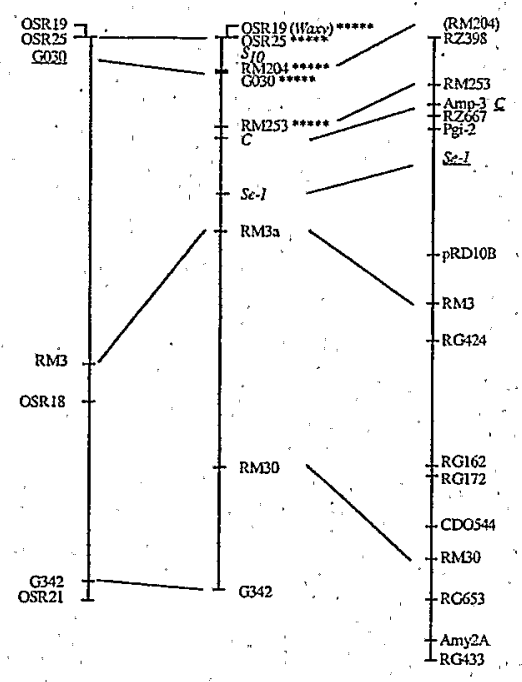



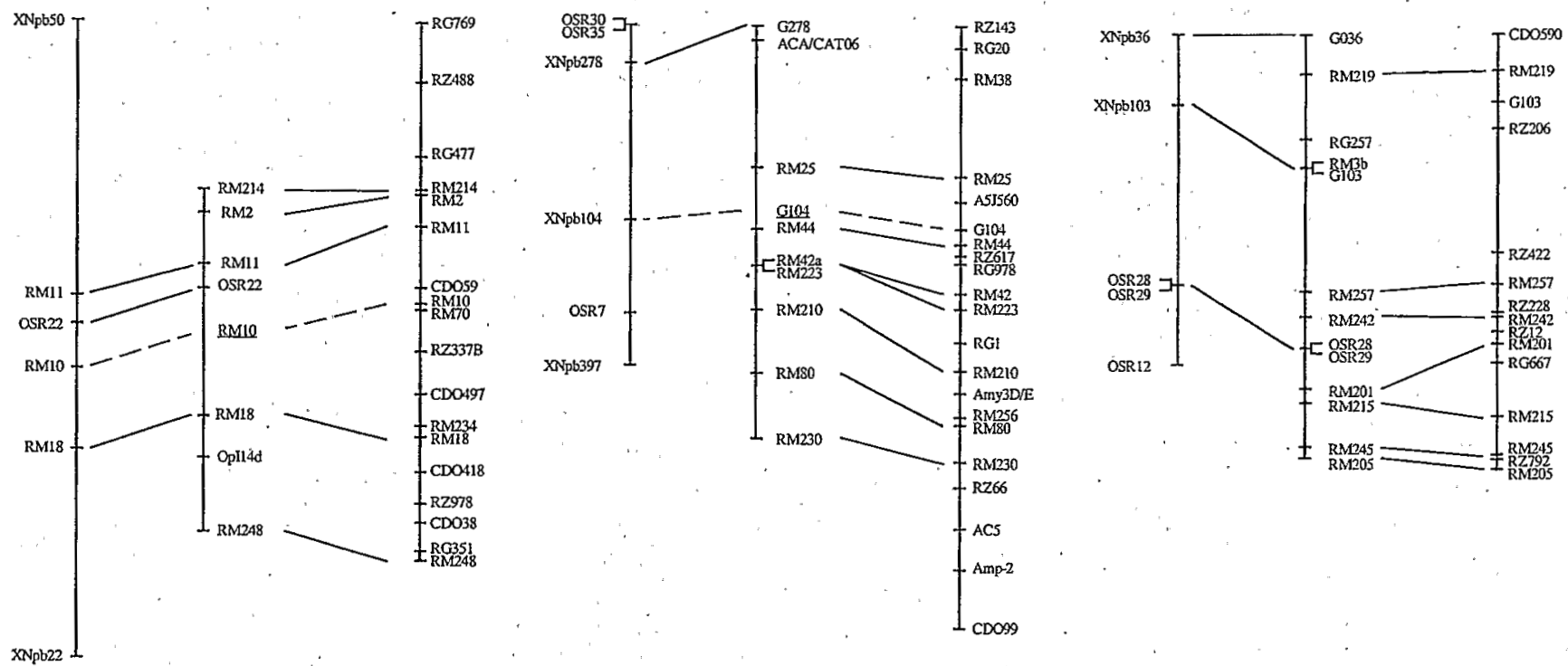

10

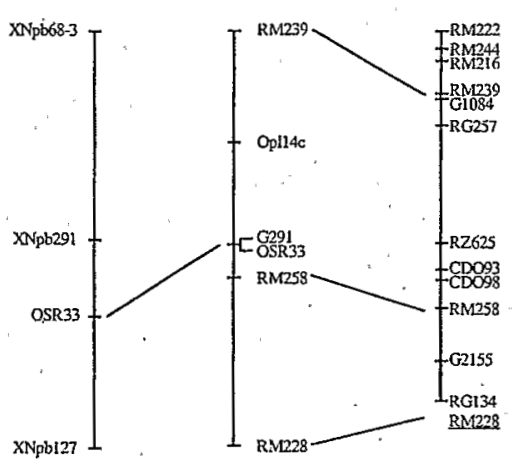

11

12
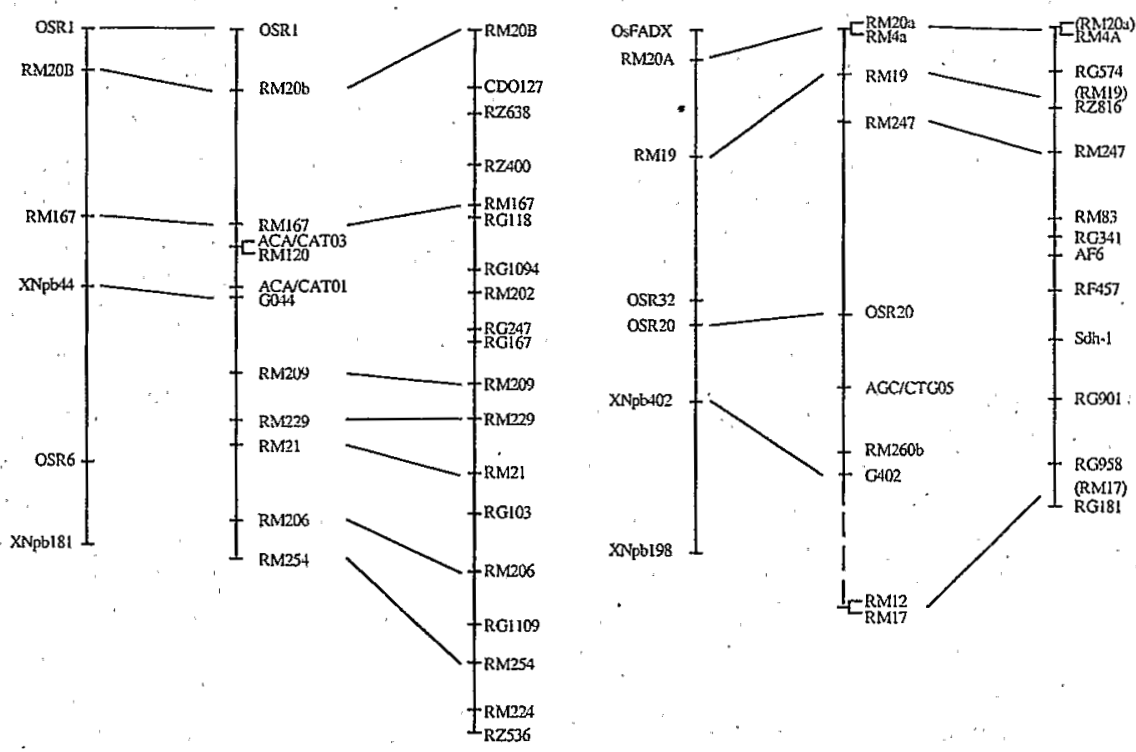

Fig. 1 PCR-based genetic map developed from a backcross population (O. sativalO. glaberrimal/O. sativa) and its comparison with two other rice genetic maps. Linkage groups are oriented as in Chen et al. (1997). Left linkage groups: RFLP-based microsatellite map developed on a $\mathrm{RL}_{1}$ population by Akagi et al. (1996). Center linkage groups: microsatellite-based map developed on a $\mathrm{BC}_{1}$ population (present study). Right linkage groups: RFLPbased microsatellite map developed on a $\mathrm{DH}_{1}$ population by Chen et al. 1997. Markers underlined are placed by inference from another mapping population. Markers in parenthesis on the $\mathrm{DH}_{1}$ map are in their most-probable position but with a LOD $<2$. Common markers between maps are joined by a plain line or by a dashed line when marker position is inferred in the $\mathrm{BC}_{1}$ map from positions in $\mathrm{RIL}_{1}$ and $\mathrm{DH}_{1}$ maps. The stars ('冰*****') following markers on chromosome 6 indicate a $P<0.00001$ for $\chi^{2}$ testing the deviation from Mendelian segregation. No segregation distortion was observed for other chromosomes

gametophytic sterility factor, $s_{I 0}$, which was already found to be tightly linked to waxy (Sano 1990). The main effect of this factor is that, in heterozygous genotypes, male gametes are systematically eliminated, and female gametes carrying the $O$. glaberrima allele for $s_{10}$ are selected against compared to gametes carrying the $O$. sativa allele. In our $\mathrm{BC}_{1}$ population, this resulted in a very large proportion (95.4\%) of heterozygous plants at markers close to $s_{10}$. We inferred the approximate position of $s_{10}$ from marker segregation ratios (Fig. 1). This location corresponds well with that found by Sano (1990). It has been shown that segregation distortion caused by a single locus, or by a locus cluster acting mainly as a single locus, has theoretically no impact on 
Table 2 Summary of major gene or QTL positions found by interval-mapping analysis in $\mathrm{BC}_{1}$ population and their possible correspondance with previously mapped genes

\begin{tabular}{|c|c|c|c|c|c|c|c|}
\hline Trait ${ }^{a}$ & Chromosome & $\begin{array}{l}\text { Marker or } \\
\text { interval }\end{array}$ & $\begin{array}{l}\text { LOD } \\
\text { score }\end{array}$ & $\mathrm{R}^{2 b}$ & Pop. sizec. & Gene nature & $\begin{array}{l}\text { Corresp. major } \\
\text { gened }^{d}\end{array}$ \\
\hline HTR & 1 & OSR23 & 13.28 & 52.6 & 64 & Major gene & $s d l$ \\
\hline HTR & 3 & RM148/RM418 & 2.32 & 20.4 & 101 & QTL & \\
\hline FT & 6 & RM253/RM3 & 20.49 & 66.4 & 143 & Major gene & $\mathrm{Se}-1$ \\
\hline RI & 6 & RM3/RM30 & 5.61 & 72.1 & 49 & Major gene & Unknown \\
\hline$\hat{R ~ I}$ & 8 & RM210/RM80 & 2.10 & 24.2 & 48 & QTL & \\
\hline AWN & 4 & RM241/RM252 & 5.46 & 24.0 & 98 & Major gene & $A w n-I$ \\
\hline AWN & 8 & RM080 & 5.51 & 26.8 & 70 & Major gene & Awn-4 \\
\hline COLste & 6 & RM253/RM3 & 15.59 & 40.8 & 141 & Major gene & $C$ \\
\hline COLsti & 6 & RM253/RM3 & 34.93 & 69.4 & 139 & Major gene & $C$ \\
\hline
\end{tabular}

a Trait: HTR: mean hight of the three tallest panicules; $\mathrm{R} \mathrm{I}$ : mean number of primary branching on three panicules; AWN: awning of spikelets (three classes); FT: flowering time in decreasing day length (which was mainly governed by a photosensitivity gene as plants were cultivated at the end of summer, i.e. in long days followed by short days); COLste: stem base coloration (two classes); COLsti: stigmate coloration (three classes); COLap: apiculus coloration (two classes)

$\mathrm{B}^{2}$ : percentage of variation of the trait explained by the QTL or major gene

c Pop. size: population size for which both marker and trait data were available

d Corresp. major gene: possible correspondance with known genes localised in other studies (Kinoshita 1995)

Table 3 Comparison of map lengths between interspecific (IR64/Tog5681//IR64) and intraspecific (IR64/Azucena) rice genetic maps. The majority of chromosomes have similar sizes, especially when considering the MCISc. Chromosomes 6 and 11 show a lower mean recombination rate in the interspecific hybrid, and chromosome 5 shows a lower mean recombination rate in the intraspecific hybrid

\begin{tabular}{|c|c|c|c|c|c|c|c|c|c|}
\hline \multirow{2}{*}{$\begin{array}{l}\text { Chromo- } \\
\text { some }\end{array}$} & \multirow{2}{*}{$\begin{array}{l}\text { Marker } \\
\text { number }\end{array}$} & \multirow{2}{*}{$\begin{array}{l}\text { Discrete } \\
\text { point } \\
\text { number }\end{array}$} & \multicolumn{3}{|l|}{ TLGS } & \multicolumn{4}{|l|}{$\mathrm{MCIS}^{\mathrm{c}}$} \\
\hline & & & $\mathrm{BC}_{1} \mathrm{~d}^{\prime}$ & $\mathrm{DH}_{1}{ }^{\mathrm{e}}$ & $\begin{array}{l}\mathrm{BC}_{1} / \\
\mathrm{DH}_{1}\end{array}$ & Interval & $\mathrm{BC}_{1}$ & $\mathrm{DH}_{1}$ & $\begin{array}{l}\mathrm{BC}_{1} / \\
\mathrm{DH}_{1}\end{array}$ \\
\hline 1 & 12 & 12 & 191.3 & 194.3 & 0.98 & RM220-RM212 & 132.6 & 141.3 & 0.94 \\
\hline 2 & 17 & 13 & 233.1 & 198.4 & 1.17 & RM233A-RM48 & 228.2 & 189 & 1.21 \\
\hline 3 & 16 & 14 & 259.7 & 259 & 1.00 & RM60-RG418 & 252.7 & 259 & 0.98 \\
\hline 4 & 4 & 4 & 117.1 & 158.2 & 0.74 & RM261-RG143 & 117.1 & 126.9 & 0.92 \\
\hline 5 & 14 & 11 & 226.6 & 155 & 1.46 & RM13-RM26 & 195.9 & 124.8 & 1.57 \\
\hline 6 & 8 & 7 & 145.6 & 163.5 & 0.89 & RM253-RM30 & 89.5 & 125.6 & 0.71 \\
\hline 7 & 7 & 7 & 97.1 & 146 & 0.67 & RM214-RM248 & 97.1 & 100.6 & 0.97 \\
\hline 8 & 9 & 8 & 111.7 & 163 & 0.69 & RM25-RM230 & 73.8 & 77.5 & 0.95 \\
\hline 9 & 13 & 11 & 115.1 . & 117.9 & 0.98 & RM219-RM205 & 104.3 & 108.4 & 0.96 \\
\hline 10 & 6 & 5 & 101.7 & 90.6 & 1.12 & RM239-RM258 & 60.4 & 52.1 & 1.16 \\
\hline 11 & 13 & .12 & 129.4 & 172.3 & 0.75 & RM20B-RM254 & 114.5 & 155. & 0.74 \\
\hline 12 & .10 & 8 & 194.8 & 116.9 & 1.67 & RM20A-RM247. & 35.4 & 29.8 & 1.19 \\
\hline \multicolumn{2}{|c|}{ Total (cM) } & & 1923.2 & 1935.1 & & & 1501.5 & 1490.0 & \\
\hline
\end{tabular}

a Discrete point number: number of discrete loci defined by non-cosegregating markers on a linkage group

b TLGS: total linkage group size in centimorgans

c MCIS: interval on a linkage group defined by the two extreme common markers between the two maps (in centimorgans)

${ }^{\mathrm{a}} \mathrm{BC}_{1}$ : (IR64/Tog5681//IR64) backcross population

e $\mathrm{DH}_{1}$ : (IR64/Azucena) doubled-aploid population

the estimation of recombination fractions of neighbour intervals (Lorieux et al. 1995). This has been numerically confirmed for chromosome 6 in comparing the classical estimate to other estimates taking into account different allelic selection patterns using the MapDisto program. For the other chromosomes, segregations followed Mendelian expectations. The classical estimate implemented in Mapmaker v. 3.0 was thus kept for all chromosomes.
Trait analysis

The combined analysis of phenotypic and molecular data permitted us to identify major genes and QTLs responsible for three quantitative traits (height, flowering time, number of primary branches) and for three qualitative traits (awning, coloration of the stem base and coloration of the stigma) (see Table 2 for details). When possible, we tried to establish correspondences with major genes which have already been mapped [see Kinoshita (1995) for a report of genes located in rice].

For all three quantitative traits, interval-mapping analysis revealed the presence of a major gene. The ma- 
jor gene responsible for $53 \%$ of the variance of height and located on chromosome 1 is almost certainly $s d-1$, a semi-dwarf allele present in IR64. The QTL for height on chromosome 3 could correspond to that identified at the same location using the $\mathrm{DH}_{1}$ population (Albar et al. 1998). For flowering time, in terms of decreasing day length, the major gene on chromosome 6 corresponds to the photosensitivity gene $s e-1$.

The two genes identified for awning could correspond to $A n-1$ and An-4 that have been located on chromosomes 4 and 8 , respectively. Coloration of the stem base and the stigma are probably governed by the same gene, as they map to the same location, which is that of the previously identified gene $C$ (chromogen for anthocyanin).

No QTL was found for tillering or the number of secondary branches on the panicles, probably due to the low power of detection by reason of the limited populationsize available.

\section{Discussion}

According to our objectives, mainly the development of 'contig' lines, the coverage was satisfactory for the major part of the genome, except for chromosome 4 and the short-arm end of chromosome 7. Some gaps remain unfilled and will be filled when new microsatellite markers become available. Use of SSCP (single strand conformation polymorphism) could also be helpful to this aim. Fukuoka, et al. (1994) showed that 39 of 70 (55.7\%) STS markers showed polymorphism by this technique between two indica and japonica varieties, so we can expect that SSCP polymorphism between $O$. sativa and $O$. glaberrima will be at least 50\%. RAPD and AFLP markers can not be used extensively in an introgression backcross program, since their map location is unknown $a$ priori and as they tend to cluster in rice (Kurata et al. 1994). Moreover, AFLPs are not suitable for following genome fragments in a backcross programme, as we would generally have to generate at least four lanes per individual with only one interesting band per lane. Microsatellite markers thus represent the best choice, as they are simple to generate, highly polymorphic, locusspecific and codominant. However, their development is expensive and time-consuming and obtaining a saturated microsatellite map represents a major effort.

Our results show a very good colinearity of $O$. sativa and $O$. glaberrima species with only small non-significant marker inversions. This means that no major rearrangements like inversions or translocations have occurred between the two species. Moreover, except for local differences, the $\mathrm{BC}_{1}$ interspecific map is about the same size as the $\mathrm{DH}_{1}$ (indicaxjaponica) map. It is interesting to compare these results on recombination and colinearity with available cytogenetic studies: Morinaga and Kuriyama (1957) showed a normal behaviour of the meiotic chromosomes of $O$. sativa $\times O$. glaberrima hybrids. A recent study showed a very strong resemblance between the chromosomes of both species, with only minor cytogenetic differences (Ohmido and Fukui 1995). This genetic mapping study thus confirms that the interspecific hybrids can recombine normally along the whole genome. The region in the vicinity of the $s_{10}$ gene on chromosome 6 showed segregation distortion, which to some extent may reflect the rapid recovery of parental types and the MV linkage in the segregating population as proposed by Sano et al. (1980).

This would be very different for distant indicaxjaponica crosses, where segregation distortion can involve many chromosomal regions (Causse et al. 1994; Kurata et al. 1994; Lorietix et al. 1996; McCouch et al. 1988; $\mathrm{Xu}$ et al. 1997) and can be explained by different sets of gametophytic sterility genes (Oka 1974). In our $\mathrm{BC}_{1}$ population, it is also probable that several sterility genes are acting on pollen viability but were masked by the total elimination of male gametes due to $s_{10}$.

Nevertheless, a marker-assisted introgression strategy between the two cultivated rice species should succeed and the selection of the rare semi-fertile $\mathrm{BC}_{1}$ individuals which are homozygous for the $O$. sativa allele of $s_{10}$ is a possible starting point. In this way, the elimination of remaining gametophytic or gametic sterility genes could be achieved by a conventional process. Another. possible way to overcome hybrid sterility would be the development of doubled haploid lines by anther culture from $O$. sativa $\times O$. glaberrima $\mathrm{F}_{1} \mathrm{~s}$ or $\mathrm{BC}_{1} \mathrm{~s}$. If anther culture permits the bypass of sporo-gametophytic interaction, a higher percentage of homozygous semi-fertile DH lines could be obtained than with conventional backcrossing. The rice breeding program at the West Africa Rice Development Association (WARDA) succeeded in producing fertile DH lines from various interspecific combinations between $O$. glaberrima and both japonica and indica varieties. This suggests that interspecific sterility barriers may be efficiently overcome in this way (Jones et al. 1997).

An $O$. sativa $X O$. glaberrima linkage map may have several interesting applications. First, it permits the localisation of several genes or QTLs from 0 . glaberrima. Indeed, we were able to map several loci responsible for different traits in the $\mathrm{BC}_{1}$ progeny. Genetic mapping of resistance genes is currently being carried out for Rice Yellow Mottle Virus and for the nematode Heterodera sacchari on the basis of the present linkage map.

Second, although this species was not bred as intensively as $O$. sativa, it can carry numerous agronomically important alleles. Even if $O$. glaberrima alleles are, under optimised management conditions, often of lower value than $O$. sativa alleles when taken separately, transgressions may be produced in interspecific progeny. Such transgressions have been identified in $O$. sativa $\times$ O. rufipogon progeny (Xiao et al. 1998). For 12 agronomically important traits, the $O$. rufipogon accession was phenotypically inferior to $O$. sativa. However, transgressive segregants that outperformed the original elite hybrid variety were observed for all traits examined. Similar results were obtained in the present study. 
For instance, we observed $\mathrm{BC}_{1}$ plants with tillering at 45 days which was almost two-times higher than that of the $O$. sativa parent, IR64. This means that we may expect to identify QTLs acting in a complementary way and thus use them in a marker-assisted selection program.

Another main interest of a PCR-based $O$. sativa $O$. glaberrima map is its utility for monitoring the development of a set of introgression lines (called 'contig lines'; Ghesquière et al. 1997) containing only targeted fragments of $O$. glaberrima in an $O$. sativa genetic background. This genetic material represents a valuable genetic resource with a known genetic content, and will permit the rapid identification of major factors responsible for segregating traits between the two cultivated rice species. $\mathrm{A} \mathrm{BC}_{3}$ progeny is currently being developed, and a molecular survey of $\mathrm{BC}_{2}$ plants shows that the complete genome is represented by a small number of genotypes. The genomic regions identified using 'contig' lines will then have to be compared with those identified by QTL analysis in segregating interspecific populations.

Finally, knowledge of the $O$. sativa ssp. indica $X$. glaberrima polymorphism and of the map position of a set of PCR-based markers will permit the rapid characterisation of introgressed material obtained by a conventional backcross strategy (i.e. without the aid of molecular markers). Such material would increase the precision and the power of analyses using the material of 'contig' lines.

An additional interest of the present study is the integration in a single map of microsatellite and STS markers coming from different studies. This permits one to define a framework map with 'anchor' PCR markers regularly dispersed throughout the genome. Such a map would be useful to carry out rapid segregation studies on multiple crosses.

The present study has generated the first PCR-based $O$. sativa $\times O$. glaberrima genetic linkage map, which will constitute a valuable tool for the utilisation of $O$. glaberrima in the breeding of rice varieties adapted to the African environment.

Acknowledgements This research was supported by IRD and the Africa/Asia joint Research on Interspecific Hybridization between the African and Asian rice species (O. glaberrima and $O$. sativa) through WARDA. Many thanks to J. Bennett for having kindly provided us for STS primers aliquots and sequences.

\section{References}

Akagi H, Yokoseki Y, Inagaki A, Fujimura T (1996) Microsatellite DNA markers for rice chromosomes. Theor Appl Genet 93:1071-1077

Albar L, Lorieux M, Ahmadi N, Rimbault I, Pinel A, Sy AA, Fargette D, Ghesquière A (1998) Genetic basis and mapping of the resistance to rice yellow mottle virus. I: QTLs identification and relationship between resistance and plant morphology. Theor Appl Genet 97:1145-1154

Attere A, Fatokun C (1983) Reaction of Oryza glaberrima accessions to rice yellow mottle virus. Plant Dis 67:420-421
Causse MA, Fulton TM, Cho YG, Ahn SN, Chunwongse J, Wu K, Xiao J, Yu Z, Ronald PC, Harrington SE, Second G, McCouch SR, Tanksley SD (1994) Saturated molecular map of the rice genome based on an interspecific backcross population. Genetics 138:1251-1274

Chen X, Temnykh S, Xu Y, Cho YG, McCouch SR (1997) Develoment of a microsatellite framework map providing genomewide coverage in rice (Oryza sativa L.). Theor Appl Genet 95:553-567

Fukui K, Iijima K (1991) Somatic chromosome map of rice by imaging methods. Theor Appl Genet 81:589-596

Fukuoka S, Inoue T, Miyao A, Monna L, Zhong H, Sasaki T, Minobe X (1994) Mapping of sequence-tagged sites in rice by single-strand conformation polymorphism. DNA Res 1:271277

Ghareyazie B, Huang N, Second G, Bennett J Khush GS (1993) Comparison between PCR-based RFLP and Southern-based RFLP as DNA markers for germplasm classification in rice (Oryza sativa L.). Rice Genet Newslett 10:129-132

Ghesquière A, Séquier J, Second G, Lorieux M (1997) First steps towards a rational use of African rice, Oryza glaberrima, in rice breeding through a 'contig 'line' concept. Euphytica $96: 31-39$

Harushima Y, Yano M, Shomura A, Sato M, Shimano T, Kuboki Y, Yamamoto T, Lin S, Antonio B, Parco A, Kajiya H, Huang N, Yamamoto K, Nagamura Y, Kurata N, Khush G, Sasaki T (1998) A high-density rice genetic linkage map with 2275 markers using a single $F_{2}$ population. Genetics 148:479 494

Inoue T, Zhong HS, Miyao A, Ashikawa I, Monna L, Fukuoka $S$, Miyadera N, Nagamura $Y$, Kurata N, Sasaki T, Minobe $Y$ (1994) Sequence-tagged sites (STSs) as standard landmarkers in the rice genome. Theor Appl Genet 89:728-734

Jones M, Dingkhun M, Aluko GK, Semon M (1997) Using backcrossing and doubled haploid breeding to generate weed-competitive rices from $O$. sativa L. $\times O$. glaberrima Steud. genepools. In: Proc Wkshp Africa/Asia Joint Res on Interspecific Hybridization between the African and Asian rice species $(O$. glaberrina and $O$. sativa), WARDA, M'bé, Bouaké, Côted'Ivoire, December 16-18, 1996, pp 61-70

Kinoshita T (1995) Report of Committee on gene symbolization, nomenclature and linkage groups. Rice Genet Newslett 12:9-153

Kosambi DD (1944) The estimation of map distance from recombination values. Ann Eug 12:172-175

Kurata N, Nagamura Y, Yamamoto K, Harushima Y, Sue N, Wu J, Antonio BA, Shomura A, Shimizu T, Lin S-Y, Inoue $T$, Fukuda A, Shimano T, Kuboki Y, Toyama T, Miyamoto Y, Kirihara T, Hayasaka K, Miyao A, Monna L, Zhong HS, Tamura Y, Wang Z-X, Momma T, Umehara Y, Yano M, Sasaki T, Minobe Y (1994) A 300-kilobase interval genetic map of rice including 883 expressed sequences. Nature Genet 8:365372

Lander ES, Botstein D (1989) Mapping mendelian factors underlying quantitative traits using RFLP linkage maps. Genetics 121:185-199

Lander ES, Green P (1987) Construction of multilocus genetic linkage maps in humans. Proc Natl Acad Sci USA 84:2363-2367

Lander ES, Green P, Abrahamson J, Barlow A, Daly MJ, Lincoln SE, Newburg L (1987) Mapmaker: an interactive computer package for constructing primary genetic linkage maps of experimental and natural populations. Genomics 1:174-181

Lorieux M, Goffinet B, Perrier X, González de León D, Lanaud C (1995) Maximum-likelihood models for mapping genetic markers showing segregation distortion. 1. Backcross populations. Theor Appl Genet 90:73-80

Lorieux M, Petrov M, Huang N, Guiderdoni E, Ghesquière A (1996) Aroma in rice: genetic analysis of a quantitative trait. Theor Appl Genet 93:1145-1151

McCouch SR, Kochert G, Yu ZH, Wang ZY, Khush GS, Coffman WR, Tanksley SD (1988) Molecular mapping of rice chromosomes. Theor Appl Genet 76:815-829 
Morinaga T, Kuriyama $\mathrm{H}$ (1957) Cytogenetical studies on Oryza sativa $\mathrm{L}$. IX. The $\mathrm{F}_{1}$ hybrid of $O$. sativa $\mathrm{L}$. and $O$. glaberrima Steud Jpn J Breed 12:153-165

Murray MG, Thompson WF (1980) Rapid isolation of high molecular weight plant DNA. Nucleic Acids Res 8:4321-4325

Ndjiondjop M-N, Abar A, Fargette $D$, Fauquet $C$, Ghesquière $A$ (1999) The genetic basis of high resistance to rice yellow mot tle virus (RYMV) in cultivars of two cultivated rice species. Plant Dis (in press)

Ohmido N, Fukui K (1995) Cytological studies of African cultivated rice, Oryza glaberrima. Theor Appl Genet 91:212217

Oka $H$ (1974) Analysis of genes controlling $F_{1}$ sterility in rice by the use of isogenic lines. Genetics 77:521-534

Ooijen JW van (1992) Accuracy of mapping quantitative trait loci in autogamous species. Theor Appl Genet 84:803-811

Panaud O, Chen X, McCouch SR (1996) Development of microsatellite markers and characterization of simple sequence length polymorphism (SSLP) in rice (Oryza sativa L.). Mol Gen Genet 252:597

Pham J, Bougerol B (1993) Abnormal segregations in crosses between two cultivated rice species. Heredity 70:466-471

Portères R (1950). Vieilles agricultures de l'Afrique intertropicale. Centres d'origine et de diversification variétale primaire et berceaux de l'Agriculture antérieure au XVle siècle. Agron Trop 5:489-507

Reversat G, Destombes D (1998) Screening for resistance to Heterodera sacchari in the two cultivated rice species, Oryza sat$i v a$ and $\dot{O}$. glaberrima. Fund and Appl Nematol 21:307-317

Sano Y (1985) Sterility barriers between Oryza sativa and $O$. glaberrima. In: Rice genetics, Proc Int Genet Symp, IRRI, Los Baños, the Philippines, 27-31 May 1985, pp 109-118

Sano $Y(1990)$ The genic nature of gamete eliminator in rice. Genetics 125:161-191
Sano Y, Chu Y, Oka H (1979) Genetic studies of speciation in cultivated rice. 1 . Genic analysis for the $F_{1}$ sterility between $O r y$ $z a$ sativa and $O$. glaberrima Steud. Jpn J Genet 54:12:1-132

Sano Y, Chu Y, Oka H (1980) Genetic studies of speciation in cultivated rice. 2. Character variations in backcross derivatives between Oryza sativa and $O$. glaberrima: $\mathrm{M}-\mathrm{V}$ linkage and key characters. Jpn J Genet 55:19-39

Sano Y, Sano R, Morishima H (1984) Neighbour effects between two occurring rice species, Oryza sativa and $O$. glaberrima. J Appl Ecol 21:245-254

Second $G$ (1982) Origin of the genic diversity of cultivated rice (Oryza spp.): study of the polymorphism scored at 40 isozyme loci. Jpn J Genet 57:25-57

Second G (1985) Evolutionary relationships in the Sativa group of Oryza based on isozyme data. Génét Sél Evol 17:89-114

Vos $P$, Hogers R, Bleeker M, Reijans M, van de Lee T, Hornes $M$ Fritjers A, Pot J, Peleman J, Kuiper M, Zabeau M (1995) AFLP : a new technique for DNA fingerprinting. Nucleic Acids Res 23:4407-4414

Wu K, Tanksley S (1993) Abundance, polymorphism and genetic mapping of microsatellites in rice. Mol Gen Genet 241:225235

Xiao J, Fulton T, McCouch S, Tanksley S, Kishimoto N, Ohsawa $R$, Ukai Y, Saito A (1992) Progress in integration of the molecular maps of rice. Rice Genet Newslett 9:124-128

Xiao J, Li J, Grandillo S, Ahn S, Yuan L, Tanksley S, McCouch S (1998) Identification of trait-improving quantitative trait loci alleles from a wild rice relative, Oryza rufipogon. Genetics 150:899-909

Xu Y, Zhu L, Xiao J, Huang N, McCouch S (1997) Chromosomal regions associated with segregation distortion of molecular markers in $F_{2}$, backcross, doubled haploid, and recombinant inbred populations in rice (Oryza sativa L.). Mol Gen Genet 253:535-545 


\section{THEORETICAL AND APPLIED GENETICS}

\section{International Journal of Plant Breeding Research}

\section{Volume 100 Number 3-4 February 2000}

Goldman IL, Austin D: Linkage among the $R, Y$ and $B I$ loci in table beet 337

Tang S, Li Z, Jia X. Larkin PJ. cenomic in situ hybridization (GISH) analyses of Thinopyrum intermedium, its partial amphiploid Zhong 5, and disease-resistant derivatives in wheat 344

- Linares $\mathrm{C}$, Irigoyen ML, Fominaya As Identification of C-genome chromosomes involved in intergenomic translocations in Avena sativa $L$, using cloned repetitive DNA sequences 353

Pedrosa A, Schweizer D, Guerra M Cytological heterozygosity and the hybrid origin of sweet orange [Citrus sinensis (L.) Osbeck] 361

Zheng Y, Stommel JR: RAPD and AFLP tagging and mapping of Beta $(B)$ and Beta modifier $\left(\mathrm{MO}_{\mathrm{O}}\right.$ ), two genes which infilience B-carotene accumulation in fruit of tomato (Lycopersicon) esculentum Mill.) : 368

Nagano H Kawasaki S, Kishima Y Sano Y, structural differences in the vicinity of the waxy locus among the Oryza species with the AA-genome identification of variable regions $376^{\circ}$

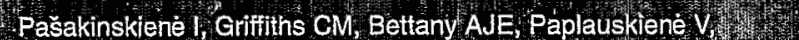
Humphreys MW: Anchored simple-sequence repeats as piners to generate species-specific DNA markers in Loltum and Festuoa grasses 384

H.

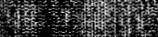

Kondo T, Terada $K$, Hayashi E, Kuramoto N, Okamura M, Kawasaki $H$ : RAPD markers linked to a gene for resistance to pine needle gall midge in Japanese black pine (Pinus thunbergin) 391 ,

Masci S, D'Ovidio A, Lafiandra D, Kasarda DD: A 1 B-coded low-molecular-weight glutenin subunit associated with quality in durum wheats shows strong similarity to a subunit present in some bread wheat cullivars 396

Singh RP. Nie $X$, Tai GCC: A novel hypersensitive resistance response against potato virus $A$ in cultivar "Shepody" 401 Jiang $C$, Wright RJ, Woo SS, DelMonte TA, Paterson AH QTL analysis of leaf morphology in tetraploid Gossypium (cotton) 409

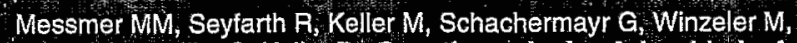
Zanetti $S$, Feuillet $C$, Keller $B$. Genetic analysis of durable leaf rust resistance in winter wheat 419

sy

$$
D \text { o } 44
$$

$\operatorname{TSSH}=0040-5752$
Reamon-Büttner SM, Jung C: AFLP-derived STS markers for the identifioation of sex in Asparagus officinalis L. 432

Boiteux LS, Belter JG, Roberts FA, Simon PW: RAPD linkage map of the genomic region encompassing the root-knot nematode (Meloidogyne javanica) resistance locus in carrot 439

Gastaison JP, Yano M: cenetic mapping of hypervariable minisatellite sequences in rice (Oryza sativa L.) 447 .

Parani $M$, Lakshmi $M$, Zlegenhagen $B$, Fladung $M$, Senthilkumar $P$, Parida A: Molecular Phylogeny of mangroves VIl. PCR-RFLP of trrs-psbC and $r b c L$ gene regions in 24 mangrove and mangroveassociate species 454

$$
\text { (1) }
$$

Yin Z, Wang G-L: Evidence of multiple complex patterns of T-DNA integration into the rice genome, 461

Monforte AJ, Tanksley SD: Fine mapping of a quantitative trait locus (QTL) from Lycopersicon hirsutum chromosone taffecting fruit characteristics and agronomic traits: breaking linkage among QTLs affecting different traits and dissection of heterosis for yield 471

Heusden AW van, Shigyo M, Tashiro Y, Vrielink-van Ginkel R, Kik $C$ : AFLP linkage group assignment to the chromosomes of Allium cepa L. via monosomic addition lines 480

Poirier $Y$, Ventre G, Nawrath C. High-frequency linkage of co-expressing T-DNA in transgenic Arabidopsis thaliana transformed by vacuum- infiltration of Agrobacterium tumefaciens 487

Börner A, Chebotar S, Korzun V: Molecular characterization of the genetic integrity of wheat (Triticum aestivum $L$ ) germplasm after long-term maintenance 494

Sefc KM, Lopes MS, Lefort F, Botta R, Roubelakis-Angelakis KA, lbáñez J; Pejić I, Wagner HW, GlössI J; Steinkellner H: Microsatelitite variability in grapevine cultivars from different European regions and evaluation of assignment testing to assess the geographic origin of cultivars 498 .

Linacero A, Freitas Alves E, Vázquez AM: Hot spots of DNA instability revealed through the study of somacional variation in rye 506

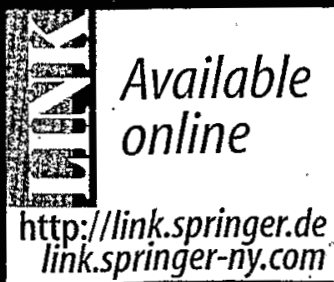


